\title{
REseñas
}

\section{LA CONSTITUCIÓN MULTICULTURAL}

Daniel Bonilla Maldonado

Bogotá: Universidad de los Andes-Pontificia Universidad Javeriana-Instituto Pensar-Siglo del Hombre Editores, 2006, 298 p.

Traducción del inglés por Magdalena Holguín y Daniel Bonilla

LA CONSTITUCIÓN MULTICULTURAL OFRECE UNA REFLEXIÓN EN TORNO A LA PREgunta sobre cómo se debe organizar la esfera pública de sociedades liberales que se definen como multiculturales. Es decir, sobre cómo se organizan los espacios, los mecanismos y las formas de interacción social a partir de las cuales se construye un discurso público, en este caso sobre la diversidad cultural, en una sociedad determinada, Colombia. Específicamente, Bonilla elabora su reflexión a partir de la forma en que se han tratado dos tensiones existentes en los discursos académicos e institucionales sobre la diferencia cultural, que él considera fundamentales. A saber, la tensión existente entre diversidad cultural y valores liberales por un lado, y entre unidad y diversidad cultural, por otro.

La reflexión se hace por medio de un corpus analítico conformado por tres tipos de fuentes: la teoría política contemporánea, los proyectos que presentaron los delegados indígenas a la Asamblea Nacional Constituyente (ANC) y las sentencias emitidas por la Corte Constitucional, acompañadas de los salvamentos de voto de los magistrados. Estas fuentes determinan el hilo argumentativo y el orden de los capítulos propuestos por el autor, quien parte de la teoría política (capítulo I), pasa a las discusiones que se dieron durante la ANC (capítulo 2), sigue con las sentencias de la Corte Constitucional (capítulos 3 y 4) y cierra proponiendo cinco criterios normativos, con los que pretende contribuir a colmar el vacío teórico y las debilidades jurídicas que ha afrontado la Corte desde la proclamación de la Constitución política de rg9r. Sin embargo, es menester mencionar que el libro presenta una fisura pocas veces superada por el autor, entre la discusión de los filósofos liberales, presente en el primer capítulo, y la de los proyectos presentados a la ANC o de las sentencias de la Corte, desarrolladas en los tres capítulos siguientes. Así, el intento por 
considerar el trabajo de los delegados a la Asamblea y de los magistrados de la Corte como producción de teoría es opacado por el peso que se da a las propuestas de los filósofos, que implícitamente actúan como marco de referencia interpretativo a lo largo del libro.

El primer capítulo presenta un análisis detallado de las propuestas sobre el multiculturalismo de Ch. Taylor, W. Kymlicka y J. Tully, considerados los principales exponentes contemporáneos del pensamiento liberal y cuyos trabajos representan tres aproximaciones a la tensión entre la diversidad cultural y los valores liberales. Bonilla denomina los enfoques de estos autores, respectivamente, liberalismo sustantivo, liberalismo multicultural y constitucionalismo moderno. Su análisis muestra la posición de cada uno de estos filósofos frente al liberalismo, las categorías que utilizan o construyen en esta toma de posición, la solución o enfoque propuesto, así como los límites para pensar la diferencia cultural cuando de sociedades iliberales se trata. De hecho, son estos límites los que constituyen aquello que denomina la tensión entre diversidad cultural y los valores liberales.

En este capítulo es de anotar la advertencia del autor sobre el verdadero objetivo de dichos teóricos, cuya pregunta común no es cómo pueden convivir diferentes culturas de una manera justa, sino cómo pueden hacerlo diferentes culturas liberales (5I). Esta salvedad implica que las propuestas de los tres filósofos en cuestión presuponen que todas las sociedades comparten ciertos valores liberales, al tiempo que permite comprender plenamente una de las conclusiones del capítulo, a saber, el fracaso que experimentan tales enfoques en el intento de pensar la inclusión de la diferencia radical o de las sociedades iliberales; es decir, aquellas que no comparten los principios morales y políticos básicos del liberalismo, como los derechos individuales y la democracia.

En el segundo capítulo se examina el proceso por el cual la tensión entre unidad y diversidad cultural quedó asentada en la Constitución política durante la Asamblea Nacional Constituyente. Se parte del análisis de los proyectos presentados por los delegados indígenas Francisco Rojas Birry, Lorenzo Muelas y Francisco Peña, y se cierra con un comentario sobre la forma en que tal tensión se refleja en los artículos de la nueva Constitución y las posibles razones que llevaron al conjunto de delegados a la ANC a plasmarla de forma acrítica. En este sentido, el análisis de los proyectos permite a Bonilla identificar y problematizar la 
coexistencia de argumentos que sustentan la defensa tanto de la igualdad y la unidad política como de la diferencia cultural y la autonomía política. El autor llama la atención sobre este hecho, ya que estos principios no pueden coexistir y tampoco se pueden alcanzar simultáneamente. Al menos no desde de la teoría política liberal que él defiende, ya que desde esta perspectiva el principio de igualdad implica respetar los derechos individuales de los miembros/individuos de las minorías culturales, mientras que el principio de la diferencia propende a reconocer las ideas morales y políticas de los grupos. Así, el autor subraya la falta de claridad teórica de los delegados a la Asamblea, no sólo indígenas, pues no encuentra propuestas sobre cómo afrontar tal contradicción. Es más, durante la Asamblea no hubo discusión alguna al respecto.

Bonilla muestra de forma clara el uso que los delegados indígenas hacen de estos principios en sus proyectos. Así, para ellos, defender la igualdad es, grosso modo, una posición contra la discriminación y en favor de la reivindicación del principio de dignidad de la persona, mientras que la defensa de la diferencia cultural busca el reconocimiento del carácter multicultural del país, de los derechos de autogobierno y de la jurisdicción indígena, así como la creación de un distrito electoral especial. Buscan la inclusión del carácter multicultural de la nación en la Constitución desde el principio de dignidad de la persona, con el fin de lograr un efecto pedagógico sobre la sociedad nacional. La solución de las posibles contradicciones o cruces jurisdiccionales entre los derechos de autonomía reclamada y las posibles decisiones nacionales por lo pronto no tienen cabida en sus propuestas.

Esta falta de reflexión es la que cuestiona y trata de entender el autor en este capítulo, ya que quedó reflejada en el articulado de la Constitución. En este sentido se subraya cómo esta última oscila entre los valores políticos de la unidad y la diversidad cultural, el reconocimiento de derechos de autogobierno y facultades jurisdiccionales y los límites impuestos y entre dichos derechos y la idea de un estado unitario. Movimiento que para algunos de los delegados no existe, pues creen en la primacía de los valores liberales y para otros debe ser resuelto en la marcha por el Congreso de la república y las altas cortes.

Ahora bien, esta tensión entre unidad y diversidad cultural recubre otras dos tensiones, entre derechos individuales y 
diferencia radical, por un lado, y entre el principio de unidad política y el reconocimiento del autogobierno de las minorías culturales por otro, que reflejan los problemas que surgen del encuentro entre la práctica política y el derecho constitucional en Colombia. Estas tensiones se abordan, respectivamente, en los capítulos 3 y 4, mediante el análisis de la jurisprudencia de la Corte Constitucional. La discusión sobre la tensión entre derechos individuales y diferencia radical se elabora a partir del análisis de las sentencias relativas a los casos de El Tambo (sentencia T-254/94), embera-chamí (T-349/96) y arhuaco (SU-510/98), mientras que aquella entre el principio de unidad política y el reconocimiento del autogobierno de las minorías culturales se expone mediante el análisis seis casos: Cristianía (sentencia T428/92), Base Militar (T-405/93), Vaupés (T-257/93), embera (T-380/93), uwa (SU-039/97) y Urrá (T-652/98).

Tomar las sentencias y los salvamentos de voto asociados como objeto de análisis es interesante, ya que son los principales mecanismos con los que la Corte Constitucional participa en la creación del discurso público sobre la diversidad cultural. Al respecto, hay que decir que el argumento del libro se ve limitado por el hecho de utilizar únicamente sentencias relacionadas con grupos indígenas; sorprende la ausencia de referencias a otros grupos étnicos, más aún porque no se hacen explícitas las razones de esta delimitación. De hecho, cabe preguntarse si las tendencias identificadas existen o no en el tratamiento que la Corte ha dado a casos relacionados con otros grupos étnicos o si acaso hay otro tipo de intereses en juego que puedan llevar a la identificación de tendencias adicionales. En fin, este es un vacío que deja el libro.

Sin olvidar entonces los límites del trabajo, encontramos que el discurso sobre la diversidad cultural de la Corte Constitucional, además de estar construido sobre las tensiones mencionadas, ha estado marcado también, siguiendo al autor, por varios movimientos o tendencias interpretativas. Así, la resolución de la primera tensión ha pasado del liberalismo puro (El Tambo), al interculturalismo radical (embera-chamí) y finalmente al liberalismo cultural (arhuaco), mientras que en la segunda tensión se va del individualismo ciego (Cristianía), al centralismo militante (Base Militar) y por último a la autonomía colectiva radical (Vaupés, embera, uwa y Urrá). Dado que salvo el último movimiento los demás están sustentados en un solo ejemplo, vale la pena 
preguntarse hasta qué punto es pertinente o no hablar de movimientos de la Corte en la resolución de las tensiones abordadas en estos capítulos. Ciertamente el autor cita, en notas a pie de página, sentencias que en su entender sirven de apoyo a la idea de la existencia de un corpus de decisiones tomadas en conjunto y con conciencia de los cambios de un caso a otro. Sin embargo, no las toma en cuenta en su exposición y sólo presenta casos puntuales en los que se aprecian los titubeos de los magistrados y la influencia de sus posiciones éticas y políticas en las decisiones que quedarán plasmadas en las sentencias. De hecho, el análisis tal y como está presentado refleja, sobre todo, la contingencia de las decisiones de la Corte y en ningún momento una actitud conjunta o coherencia que pueda sustentar la idea de movimientos o, en nuestros términos, tendencias interpretativas. Falta de coherencia a la que el autor mismo se refiere en la conclusión, en la que propone los criterios que a su juicio deberían guiar las interpretaciones de la Corte.

No obstante lo anterior, el análisis propuesto en estos capítulos es interesante al menos en dos sentidos. Primero, porque acerca al lector a la racionalidad puesta en marcha por los magistrados en la conceptualización que hacen de cada caso. Conceptualización que comprende desde la definición de los derechos en disputa hasta la argumentación que llevará a la solución del caso. En cuanto a la identificación de los derechos en disputa se refiere, Bonilla muestra con claridad cómo el discurso sobre la diversidad cultural ha sido construido hasta ahora sobre una serie de derechos y argumentos estrictamente liberales, lo cual lleva al hecho de proteger los principios del liberalismo más que los de la diversidad cultural; esto, independientemente de que el fallo sea a favor de los grupos indígenas. Por ejemplo, casos cuyo asunto principal es la autonomía territorial son resueltos mediante la invocación del derecho a la propiedad privada, a la vida o bien acudiendo a posibles riesgos culturales, sociales y económicos. Derechos que terminan desviando la atención del problema central, es decir, el reconocimiento de la diversidad cultural.

Segundo, el análisis elaborado en estos capítulos permite acercarse al vocabulario con el que la Corte Constitucional, es decir los magistrados, piensan y se refieren a la diferencia cultural. De especial interés son las nociones que se manejan sobre términos como grupos étnicos, comunidad y cultura, en las que infortunadamente Bonilla también queda atrapado. De hecho, el 
antropólogo lector no puede evitar una ligera sonrisa frente al embarazo que parece experimentar el autor al momento de referirse a las sociedades indígenas, pues ante sus ojos se despliega un arsenal de términos utilizados como sinónimos que lo hacen pensar en la historia de la disciplina y en el poco impacto que la investigación antropológica contemporánea parece tener en los espacios en los cuales se crea el discurso público sobre la diversidad cultural, como lo deja ver la bibliografía utilizada por el autor. Así, la diferencia radical de la teoría liberal es nombrada indistintamente bajo los términos de minorías culturales, tribus indígenas, grupos aborígenes, grupos indígenas, comunidades indígenas, comunidades aborígenes, comunidades culturales o simplemente tribu, cuando de un caso específico se trata. Todos estos términos funcionan como sinónimos en la medida en que son conceptualizados bajo el concepto de comunidad tradicional que es opuesto al de comunidad liberal, siendo los criterios de definición el lugar que se otorga al individuo en el universo, el tipo de relación entre el individuo y el grupo y la existencia o no de límites bien definidos entre la esfera privada y la esfera pública. A pesar de reconocer que no todos los grupos indígenas son iguales, que se han ido transformado a lo largo de la historia e incluso que existen comunidades híbridas, Bonilla define siempre las comunidades tradicionales con criterios estrictamente liberales como los recién señalados.

Bonilla concluye su trabajo proponiendo cinco criterios normativos con los cuales pretende "contribuir a neutralizar las debilidades de la jurisprudencia de la Corte y ayudar a estructurar interpretaciones de la Constitución que permitan un reconocimiento justo y una apropiada acomodación de la diversidad cultural” (p. 27I). Tales criterios son: I) imparcialidad del estado frente a las comunidades culturales; 2) maximización del derecho de autogobierno de los grupos indígenas; 3) mínima intervención del estado y máxima de la sociedad civil; 4) estrategia de salida o posibilidad de abandonar la comunidad; y 5) diálogos interculturales para transformar la coexistencia de diferentes culturas. Al respecto, vale la pena mencionar que aun cuando estos criterios buscan potencializar el reconocimiento de las diferencias culturales, trazan también algunos límites a su ejercicio. En particular, el autogobierno puede ser limitado cuando la prohibición de la tortura, el asesinato y la esclavitud, pilares de una moralidad mínima en Colombia según el autor, corren el riesgo de ser violados. Por 
otra parte, dichos criterios buscan que el estado actúe siempre de forma imparcial, asegurando la distribución de recursos de forma justa y garantizando el equilibrio entre los intereses y las necesidades de las culturas que conforman la nación mediante la promoción de diálogos interculturales. En síntesis, esta propuesta normativa busca profundizar el reconocimiento de la diversidad siempre y cuando los valores de las comunidades culturales no atenten contra los derechos del individuo, entendido en clave liberal. Paradójicamente, falta aquí una reflexión sobre las relaciones entre derechos sociales, culturales y este nuevo individuo genérico.

En síntesis, la fortaleza del libro reside entonces en un análisis de la jurisprudencia de la Corte Constitucional que resalta la historicidad del discurso que la institución encargada de interpretar la Constitución política ha creado hasta ahora sobre la diversidad cultural. Acceder a esta construcción suscita en el lector algunas reflexiones sobre la contingencia de dicho discurso y sobre la forma en que realmente se ha pensando y actuado en torno del reconocimiento de la alteridad durante los últimos quince años. Esto, más allá de las buenas palabras plasmadas en nuestra carta de derechos.

Álvaro Andrés SANToyo

Investigador

Grupo de antropología social, ICANH 